\title{
PPAR- $\gamma 2$ Pro12Ala Variant Is Associated with Greater Insulin Sensitivity in Childhood Obesity
}

\author{
RAFFAELLA BUZZETTI, ANTONIO PETRONE, ASSUNTA M. CAIAZZO, IRENE ALEMANNO, \\ SARA ZAVARELLA, MARCO CAPIZZI, CHARLES A. MEIN, JOHN A. OSBORN, \\ ANDREA VANIA, AND UMBERTO DI MARIO \\ Endocrinology, Department of Clinical Sciences [R.B., A.P., I.A., S.Z., M.C., U.D.M.], Center for \\ Nutrition and Dietetics of the Department of Paediatrics [A.M.C., A.V.], University of Rome, "La \\ Sapienza," 00161 Rome, Italy, Genome Centre [A.P., C.A.M.], St. Bartholomew's and the Royal London, \\ Queen Mary University of London, ECIM 6BQ London, UK, Department of Public Health Sciences \\ [J.A.O.], University of Rome, “La Sapienza," 00185 Rome, Italy
}

\begin{abstract}
ABST
Several genetic variants of peroxisome proliferator-activated
receptor- $\gamma 2$ (PPAR- $\gamma 2$ ), a molecule known to be involved in
transcription of target genes, have been identified. Pro12Ala, a
missense mutation in exon 2 of the gene, is highly prevalent in
Caucasian populations. Conflicting conclusions about the asso-
ciation between this mutation and complex traits such as obesity,
insulin sensitivity, and T2DM have been reported. We have
investigated the association of PPAR- $\gamma 2$ Pro12Ala polymor-
phism with measures of insulin sensitivity in a population of
Italian obese children ( $n=200$; mean age, $10.38 \pm 2.8$ y) in
whom clinical and biochemical analyses were performed. To
estimate the insulin sensitivity status, the homeostasis model
assessment of insulin resistance (HOMA-IR) was calculated in
all subjects. The effect of the Pro12Ala polymorphism on quan-
titative variables was tested using multiple linear regression
analysis. The frequency of Ala carriers was 17\%, similar to that
reported in other adult Caucasian populations. The X12Ala
(either Pro12Ala or Ala12Ala) genotype was associated with
\end{abstract}
significantly lower fasting insulin levels compared with Pro/Pro $(p=0.008)$. Consistent with this finding, significantly lower HOMA-IR was observed in X12Ala carriers $(p=0.023)$. In conclusion, our observations demonstrate that the X12Ala variant is significantly associated with greater insulin sensitivity in childhood obesity. Because obesity is one of the most important risk factors for cardiovascular diseases and type 2 diabetes, obese children, who are presumably at a higher risk, may be protected from these diseases by the phenotypic effect of the Ala 12 allele on insulin resistance. (Pediatr Res 57: 138-140, 2005)
BMI, body mass index
Abbreviations
BMI-SDS, BMI-standard deviation score
HOMA-IR, homeostasis model assessment of insulin resistance
PPAR- $\boldsymbol{\gamma} \mathbf{2}$, peroxisome proliferator-activated receptor- $\boldsymbol{\gamma} 2$ T2DM, type 2 diabetes

There is increasing recognition that defects in tissue sensitivity to insulin are a key factor in predisposing individuals to common disorders such as hypertension, dyslipidemia, and T2DM, ultimately contributing to increase the risk of atherosclerosis in the general population (1). The mechanisms underlying insulin resistance are not fully known, but obesity and genetic factors seem to be of great significance. In the search for genes that influence insulin sensitivity in individuals, those playing a role in adipose tissue metabolism may be recognized as good candidates.

Received June 4, 2004; accepted July 18, 2004.

Correspondence: Raffaella Buzzetti, M.D., Endocrinology, Department of Clinical Sciences, University of Rome "La Sapienza," Viale del Policlinico 155, 00161, Rome, Italy; e-mail: raffaella.buzzetti@uniroma1.it

Supported, in part, by a grant from the Italian Ministry of Health (ICS 030.6/RF00-49). DOI: 10.1203/01.PDR.0000147728.62185.21
The development and metabolism of adipocytes are regulated in a complex manner and the important role of the transcription factor PPAR- $\gamma$ has been recently recognized. PPAR- $\gamma$ are members of the nuclear hormone receptor family of transcription factors, which are known to be involved in transcription of target genes (2). PPAR- $\gamma 2$ is specific for adipose tissue; this characteristic makes it a candidate gene for the regulation of insulin and glucose metabolisms. Among genetic variants identified in the PPAR- $\gamma 2$ gene, the Pro12Ala variant is highly prevalent in Caucasians (3).

Conflicting results regarding the association between this mutation and complex traits, such as obesity, insulin sensitivity, and T2DM, have been reported so far. Some of these suggested that the X12Ala (either Pro12Ala or Ala12Ala) genotype is related to improved insulin sensitivity $(4,5)$, particularly in subgroups with obesity (6), although this conclusion is still controversial (7). 
In view of these considerations, the aim of our study was to investigate the association of PPAR- $\gamma 2$ Pro12Ala polymorphism with measures of insulin sensitivity in a population of obese children and to assess the relation of this genetic variant with the clinical and metabolic abnormalities of insulin resistance. The influence of environmental factors in a data set of children is low when compared with adults, who have been exposed to different environmental factors for much longer. The search for genetic determinants for obesity-related traits in children could increase the chance to find the responsible loci.

\section{MATERIALS AND METHODS}

Two-hundred obese children (mean age, $10.38 \pm 2.8$ y), were consecutively enrolled at the Center for Nutrition and Dietetics of the Department of Paediatrics of University "La Sapienza" (Rome) from September 2002 to April 2003. Exclusion criteria were previous diagnosis of diabetes mellitus and/or endocrine diseases.

All subjects were born in the Lazio region and were currently residing there. Parents gave their written informed consent to participate in the study after being informed of its nature. The study protocol was approved by the Ethical Committee of the University "La Sapienza" in Rome. A padiatrician (A.V.) performed the Tanner staging of puberty. The distribution of Tanner stages was as follows: prepubertal stage I: 78 ( 42 boys and 36 girls); early pubertal stage II-III: 76 (39 boys and 37 girls); and late pubertal stage IV-V: 46 (14 boys and 32 girls).

The degree of obesity was quantified using Cole's least mean square method, which normalizes the skewed distribution BMI and expresses BMI as a SD score (SDS). This measure gives age and sex-specific estimates of the distribution median $(\mathrm{M})$, the variation coefficient $(\mathrm{S})$, and the degree of skew (L) by a maximum-likelihood fitting technique (8). A complete medical history was obtained by questionnaire. Clinical (height, weight, BMI, and blood pressure) and fasting biochemical features (fasting glucose, insulin plasma levels and lipid profile, total and HDL cholesterol, and triglycerides) were evaluated at entry. Furthermore, flavored glucose in a dose of $1.75 \mathrm{~g}$ per kilogram of body weight (up to a maximum of $75 \mathrm{~g}$ ) was given orally, and blood samples were obtained for measurements of plasma glucose and insulin at 0 and $120 \mathrm{~min}$.

Serum cholesterol and triglyceride levels were determined with the Technicon RA-1000 Autoanalyzer (Technicon Instruments Corp., Tarrytown, NY); HDL was measured after precipitation of ApoB-containing lipoproteins with photungstic acid/ $\mathrm{MgCl}_{2}$. LDL-cholesterol was calculated using the Friedewald formula (9). Glucose levels were determined with the glucose oxidase method (Autoanalyzer, Beckman Coulter, Fullerton, CA). Serum insulin was measured in frozen samples (10) by RIA (Adaltis insulin kit, Adaltis, Inc., Montreal, Canada). Insulin resistance was estimated according to HOMA-IR following the formula: [(fasting insulin · fasting glucose)/22.5] (11).

Genotype analysis. Two hundred base pairs of sequence surrounding PPAR 22 Pro12Ala was provided to Applied Biosystems (Foster City, CA) to develop Taqman Allelic Discrimination (AD) Assays using their assay by design platform. Genotyping of the Pro12Ala AD was performed using primers (0.9 $\mu \mathrm{moli} / \mathrm{L}$ each) Forward 5'-TTATGGGTGAAACTCTGGGAGATT-3' and reverse 5'-TGCAGACAGTGTATCAGTGAAGGA-3' and the Taqman MGB probes Fam- TTCTGGGTCAATAGG and Vic-CTTTCTGCGTCAATAG $(0.1$ $\mu$ moli/L each; Applied Biosystems). Four microliters of a $10 \mathrm{ng} / \mu \mathrm{L}$ stock of DNA was dispensed into 384-well PCR plates using a Biomek FX robot (Beckman Coulter), to which $6 \mu \mathrm{L}$ of a mix containing primers, MGB probes, and TaqMan Universal PCR Master Mix (Applied Biosystems) were added. These were sealed with optical seals (Applied Biosystems) and incubated at $95^{\circ} \mathrm{C}$ for $10 \mathrm{~min}$ followed by 40 cycles of $95^{\circ} \mathrm{C}$ for $15 \mathrm{~s}$ and $60^{\circ} \mathrm{C}$ for $1 \mathrm{~min}$ before analysis on a $7900 \mathrm{HT}$ plate reader (Applied Biosystems). Individual genotypes were determined using SDSv2.1 software (Applied Biosystems).

Statistical analysis was performed using the SPSS statistical software, version 12 (SPSS Inc. Chicago, IL). Genotypic and allelic distributions were compared with the Pearson $\chi^{2}$ test. The effect of the Pro12Ala polymorphism on quantitative variables was tested using multiple linear regression. We adjusted values for BMI-SDS, gender, age, and pubertal stage. In addition, the effect of the interaction between genotype and BMI was included in the model. The Pro12Ala polymorphism was introduced as a dichotomous variable in the analysis. Data for insulin, triglycerides, and HOMA-IR were $\log _{10}$ transformed to normalize their distribution.

\section{RESULTS}

Observed genotype frequencies of the polymorphism were in agreement with Hardy-Weinberg expectations. The frequency of Ala allele was 9\% (Pro/Pro $=83 \%$, Pro/Ala $=16 \%$, Ala/Ala $=1 \%$ ), similar to that reported in other Caucasian populations. No significant differences in age, gender, or blood pressure were observed between the X12Ala carriers and noncarriers (Table 1). The Pro12Ala variant was not associated with differences in BMI-SDS at the $p=0.05$ level. X12Ala children showed significantly lower fasting insulin levels compared with Pro/Pro $(p=0.008)$. Consistent with this finding, a significantly lower HOMA-IR was observed $(p=0.023)$. Moreover, we observed a slight decrease (not statistically significant at the $p=.05$ level) of insulin level at $120 \mathrm{~min}$ in Ala carriers compared with noncarriers.

The lipid profile did not show any significant differences between the two groups. No significant interaction effect was observed between BMI and X12Ala polymorphism in modulating insulin sensitivity (HOMA-IR $p$ value interaction, 0.81 ; fasting insulin $p$ value interaction, 0.68).

\section{DISCUSSION}

In the present study, we have demonstrated that the common variant of PPAR- $\gamma 2$, X12Ala, is significantly associated with higher insulin sensitivity in childhood obesity. In particular, X12Ala carriers showed significantly lower insulin levels and HOMA-IR compared with noncarriers. Furthermore, we observed a decrease, although not significant, in the mean insulin level at $120 \mathrm{~min}$ of oral glucose tolerance test in Ala carriers. The X12Ala polymorphism has been variably associated with BMI $(4,7)$, insulin sensitivity $(12-14)$ and a decreased or increased risk to develop T2DM $(5,15,16)$. The first evidence for an association between the X12Ala polymorphism in

Table 1. Clinical and biochemical parameters of children subjects according to Prol2Ala PPAR- $\gamma 2$ genotype

\begin{tabular}{lccl}
\hline & & Pro/Ala or & \\
& Pro/Pro & Ala/Ala & $p^{*}$ \\
\hline No. (boys/girls) & $80 / 86$ & $15 / 19$ \\
Age (y) & $10.2 \pm 2.15$ & $10.5 \pm 2.26$ & 0.47 \\
Systolic BP (mm Hg) & $112 \pm 9$ & $110 \pm 10$ & 0.31 \\
Diastolic BP (mm Hg) & $73 \pm 7$ & $75 \pm 7.4$ & 0.21 \\
SDS-BMI & $2.78 \pm 0.71$ & $2.71 \pm 0.66$ & 0.65 \\
Fasting glucose (mmol/L) & $4.78 \pm 0.57$ & $4.76 \pm 0.59$ & 0.72 \\
2-h OGTT glucose (mmol/L) & $6.83 \pm 1.03$ & $6.71 \pm 1.09$ & 0.43 \\
Fasting insulin (mU/mL) & $24.9 \pm 11$ & $20.6 \pm 9$ & 0.008 \\
2-h insulin (mU/mL) & $92 \pm 43$ & $81 \pm 39$ & 0.11 \\
HOMA IR (arbitrary units) & $5.3 \pm 2.32$ & $4.4 \pm 1.88$ & 0.023 \\
Total cholesterol (mmol/L) & $4.29 \pm 0.82$ & $4.4 \pm 0.9$ & 0.52 \\
HDL cholesterol (mmol/L) & $1.3 \pm 0.31$ & $1.28 \pm 0.32$ & 0.72 \\
LDL cholesterol (mmol/L) & $2.61 \pm 0.65$ & $2.59 \pm 0.69$ & 0.94 \\
Triglycerides (mmol/L) & $1.07 \pm 0.51$ & $1.10 \pm 0.48$ & 0.83 \\
\hline
\end{tabular}

Data are means \pm SD.

$* p$ Values were adjusted for sex, age, SDS-BMI, Tanner stage, and BMI * PPAR- $\gamma 2$ interaction. 
PPAR- $\gamma 2$ and increased insulin sensitivity was reported by Deeb et al. (4). More recently, Koch et al. (6) observed an association of X12Ala genotype with an increase in insulin sensitivity only in the subgroup with BMI $>30$, suggesting an interaction of the polymorphism with factors originating from adipose tissue. The majority of studies have been carried out in adult populations (4,12-15), although Li et al. (17) demonstrated significant decreasing fasting insulin and HOMA-IR with increasing gene dosage of the Ala12 allele in adulthood and a similar trend, even though not significant, in childhood. The picture is still unclear, as demonstrated by several reports of either no significant association between insulin sensitivity and this variant (18) or increased insulin resistance. For example, a recent report showed a marked impairment in estimated insulin sensitivity in homozygote Ala carriers (5).

The disparate findings may be partly attributed to insufficient power in some studies, the heterogeneity of the study population in terms of clinical phenotype (lean, obese), and the type of study (population-based, clinical-based).

Our finding adds weight to previous observations of the association between insulin sensitivity and X12Ala genotypes $(4,5)$. The limitations of our study include the possibility of false-positive associations due to type 1 error, and small sample size for the analysis of qualitative traits given the allele frequency of the X12Ala allele. This may also account for the lack of statistical significance for the interaction between SDSBMI and X12Ala polymorphism, this being the same conclusion as found in a previous study (17). In conclusion, our observations suggest a protective effect of the X12Ala polymorphism of PPAR- $\gamma 2$ on insulin resistance syndrome. Inasmuch as obesity is one of the most important risk factor for cardiovascular diseases and T2DM, obese children who are presumably at a higher risk may be protected from these diseases by the phenotypic effect of the Ala 12 allele on insulin resistance.

Acknowledgments. The authors thank all patients and their families for participation.

\section{REFERENCES}

1. Ninomiya JK, L'Italien G, Criqui MH, Whyte JL, Gamst A, Chen RS 2004 Association of the metabolic syndrome with history of myocardial infarction and stroke in the third national health and nutrition examination survey. Circulation 109:42-46
2. Spiegelman BM 1998 PPAR-gamma: adipogenic regulator and thiazolidinedione receptor. Diabetes 47:507-514

3. Stumvoll M, Haring H 2002 The peroxisome proliferator-activated receptor gamma2 Pro12Ala polymorphism. Diabetes 51:2341-2347

4. Deeb SS, Fajas L, Nemoto M, Pihlajamaki J, Mykkanen L, Kuusisto J, Laakso M, Fujimoto W, Auwerx J 1998 A Pro12Ala substitution in PPARgamma2 associated with decreased receptor activity, lower body mass index and improved insulin sensitivity. Nat Genet 20:284-287

5. Altshuler D, Hirschhorn JN, Klannemark M, Lindgren CM, Vohl MC, Nemesh J, Lane CR, Schaffner SF, Bolk S, Brewer C, Tuomi T, Gaudet D, Hudson TJ, Daly M, Groop L, Lander ES 2000 The common PPARgamma Pro12Ala polymorphism is associated with decreased risk of type 2 diabetes. Nat Genet 26:76-80

6. Koch M, Rett K, Maerker E, Volk A, Haist K, Deninger M, Renn W, Haring HU 1999 The PPARgamma 2 amino acid polymorphism Pro 12 Ala is prevalent in offspring of type II diabetic patients and is associated to increased insulin sensitivity in a subgroup of obese subjects. Diabetologia 42:758-762

7. Rosmond R, Chagnon M, Bouchard C 2003 The Pro12Ala PPARgamma2 gene missense mutation is associated with obesity and insulin resistance in Swedish middle-aged men. Diabetes Metab Res Rev 19:159-163

8. Cole TJ, Bellizzi MC, Flegal KM, Dietz WH 2000 Establishing a standard definition for child overweight and obesity worldwide: international survey. BMJ 320:12401243

9. Friedewald WT, Levy RJ, Fredrickson DS 1972 Estimation of the concentration of low-density-lipoprotein cholesterol in plasma without use of the preparative ultracentrifuge. Clin Chem 18:499-502

10. Gorden P, Lesniak MA, Hendricks CM, Roth J 1973 "Big" growth hormone components from human plasma: decreased reactivity demonstrated by radioreceptor assay. Science 182:829-831

11. Matthews DR, Hosker JP, Rudenski AS, Naylor BA, Treacher DF, Turner RC 1985 Homeostasis model assessment: insulin resistance and beta-cell function from fasting plasma glucose and insulin concentrations in man. Diabetologia 28:412-419

12. Ek J, Andersen G, Urhammer SA, Gaede PH, Drivsholm T, Borch-Johnsen K, Hansen T, Pedersen O 2001 Mutation analysis of peroxisome proliferator-activated receptorgamma coactivator-1 (PGC-1) and relationships of identified amino acid polymorphisms to type II diabetes mellitus. Diabetologia 44:2220-2226

13. Jacob S, Stumvoll M, Becker R, Koch M, Nielsen M, Loblein K, Maerker E, Volk A, Renn W, Balletshofer B, Machicao F, Rett K, Haring HU 2000 The PPARgamma2 polymorphism pro12Ala is associated with better insulin sensitivity in the offspring of type 2 diabetic patients. Horm Metab Res 32:413-416

14. Frederiksen L, Brodbaek K, Fenger M, Jorgensen T, Borch-Johnsen K, Madsbad S, Urhammer SA 2002 Comment: studies of the Pro12Ala polymorphism of the PPAR-gamma gene in the Danish MONICA cohort: homozygosity of the Ala allele confers a decreased risk of the insulin resistance syndrome. J Clin Endocrinol Metab 87:3989-3992

15. Lindi VI, Uusitupa MI, Lindstrom J, Louheranta A, Eriksson JG, Valle TT, Hamalainen H, Ilanne-Parikka P, Keinanen-Kiukaanniemi S, Laakso M, Tuomilehto J; Finnish Diabetes Prevention Study 2002 Association of the Pro12Ala polymorphism in the PPAR-gamma2 gene with 3-year incidence of type 2 diabetes and body weight change in the Finnish Diabetes Prevention Study. Diabetes 51:2581-2586

16. Memisoglu A, Hu FB, Hankinson SE, Liu S, Meigs JB, Altshuler DM, Hunter DJ, Manson JE 2003 Prospective study of the association between the proline to alanine codon 12 polymorphism in the PPARgamma gene and type 2 diabetes. Diabetes Care 26:2915-2917

17. Li S, Chen W, Srinivasan SR, Boerwinkle E, Berenson GS; The Bogalusa Heart Study 2003 The peroxisome proliferator-activated receptor-gamma2 gene polymorphism (Pro12Ala) beneficially influences insulin resistance and its tracking from childhood to adulthood: the Bogalusa Heart Study. Diabetes 52:1265-1269

18. Mancini FP, Vaccaro O, Sabatino L, Tufano A, Rivellese AA, Riccardi G, Colantuon V 1999 Pro12Ala substitution in the peroxisome proliferator-activated receptorgamma2 is not associated with type 2 diabetes. Diabetes 48:1466-1468 